\title{
Rendimento e Composição Química de Carcaça da Tartaruga-da-Amazônia (Podocnemis expansa) em Sistema Comercial
}

\author{
Vera Lúcia Ferreira Luz ${ }^{1}$, José Henrique Stringhini ${ }^{2}$, Yeda Soares de Lucena Bataus ${ }^{3}$, Eder \\ Sousa Fernandes ${ }^{4}$, Wesley Assis de Paula ${ }^{5}$, Michel Neto Novais ${ }^{5}$, Isaías José dos Reis ${ }^{6}$
}

RESUMO - Foram acompanhados filhotes de Podocnemis expansa (tartaruga-da-amazônia) em oito criadouros localizados no município de Diorama, Goiás, objetivando avaliar os parâmetros de rendimento e composição química da carcaça. O experimento foi conduzido com animais, com idades entre 23 a 29 meses, os quais tiveram seu desempenho avaliado por meio de medidas biométricas do comprimento retilíneo da carapaça, em milímetros, e do peso em gramas. Foram avaliados também o rendimento e a composição química da carcaça. As análises de comparação de médias foram realizadas pelo teste de Duncan, acrescido da análise do coeficiente de correlação entre o peso corporal e o rendimento de carcaça. Os resultados apresentados apontaram que os animais com comprimento médio retilíneo da carapaça de $166,45 \mathrm{~mm}$ e peso médio de $621,35 \mathrm{~g}$ obtiveram os seguintes valores médios de rendimento: carcaça sem vísceras, $29,87 \%$; carcaça com vísceras, 46,71\%; carcaça com carapaça, 49,58\%; gordura, 5,00\%; vísceras, 16,76\%; e fígado, 2,90\%. A composição média protéica da carne correspondeu a $17,38 \%$ na matéria úmida, apresentando valor baixo de extrato etéreo (1,09\%). Observou-se que o peso corporal está fortemente correlacionado com o rendimento de carcaça $(\mathrm{r}=0,97)$.

Palavras-chave: Podocnemis expansa, rendimento de carcaça, manejo em cativeiro

\section{Evaluation of the Carcass Yield and Chemical Composition of Tartaruga-da-Amazônia (Podocnemis expansa) Kept in Commercial Systems}

\begin{abstract}
Eight Podocnemis expansa commercial flocks, all of them located at the county of Diorama State of Goiás, were monitored with the purpose of evaluating, the carcass yield parameters and chemical composition. The experiment was conducted upon animals with ages ranging from 23 to 29 months, whose performances were evaluated by taking their biometrical measures - the carapace rectilinear length in millimeters and the gain of weight in grams. It was also evaluated the carcass output and chemical composition. The comparison analysis were made using the Duncan's range test in addition to the analysis of the correlation between body weight and carcass output. The results have pointed out that the animals of $166.45 \mathrm{~mm}$ of mean rectilinear carapace length and $621.3 \mathrm{~g}$ of mean body weight obtained the following output mean values: carcass without viscera, $29.87 \%$; carcass plus viscera, $46.71 \%$; carcass plus carapace, 49.58\%; fat, $5.00 \%$; viscera, $16.76 \%$ and, liver, $2.90 \%$. The meat mean protein corresponded to $17.38 \%$ in matter, and showed a low value for the ether extract $(1.09 \%)$. A strong correlation between the body weight and the carcass output was observed $(\mathrm{r}=0.97)$.
\end{abstract}

Key Words: Podocnemis expansa, carcass output, management in captivity

\section{Introdução}

A exploração zootécnica de quelônios com fins comerciais é uma atividade recente no Brasil e tem despertado o interesse de produtores para novas formas de produção. Mais do que uma nova atividade, a criação comercial integra um conjunto de alternativas e pode contribuir para diminuir a pressão sobre os animais no ambiente natural, como também oferecer alternativas econômicas para utilização sustentada e racional dos recursos da fauna.

A espécie Podocnemis expansa (Testudines: Pelomedusidae), conhecida popularmente como tartaruga-da-amazônia, ou simplesmente tartaruga, tem desempenhado, historicamente, papel importante como recurso natural. De acordo com Alho et al. (1979), os índios foram os primeiros consumidores da carne, ovos, gordura e vísceras de tartaruga. O costume indígena foi logo estendido às populações ribeirinhas nas áreas de ocorrência dos quelônios e tornou-se um

\footnotetext{
${ }^{1}$ Parte da dissertação de mestrado em Medicina Veterinária apresentada à UFG pelo primeiro autor. Médica Veterinária do RAN/IBAMA/GO. E.mail: vera.luz@ibama.gov.br

2 Engenheiro-Agrônomo, Professor do Departamento de Produção Animal da EV/UFG. E.mail: henrique@vet.ufg.br

${ }^{3}$ Engenheira Florestal do RAN/IBAMA/GO. c

4 Químico do Laboratório de Nutrição Animal - Departamento de Produção Animal da EV/UFG.

${ }^{5}$ Acadêmico de Medicina Veterinária/UFG.

${ }^{6}$ Biólogo do RAN/IBAMA/GO. E.mail: isaias.reis@ibama.gov.br
} 
hábito alimentar da população, muitas vezes forçada a procurar as atividades extrativistas para sobreviver. A caça, que antes era apenas para consumo próprio, agora é dividida entre a família e o comércio nas cidades (Silva et al., 1997).

O interesse na criação comercial da tartaruga-daamazônia já vem desde os anos setenta, e o principal avanço nesse sentido deu-se com a legislação específica para a criação e a comercialização deste quelônio (Brasil, 1993; Brasil, 1996). Desse modo, 10\% dos filhotes produzidos em áreas naturais de desovas foram disponibilizados para a criação em cativeiro e a comercialização somente pode ser efetuada com animais a partir de $1,50 \mathrm{~kg}$ de peso vivo. Isso propiciou um incremento no número de criadouros e fez com que essa espécie passasse a figurar no cenário econômico da Região Norte, superando o número de criadouros de outras espécies silvestres (Cantarelli, 1999).

Conforme Lima (1998), a escassez de informações científicas sobre a tartaruga-da-amazônia dificulta seu cultivo em escala comercial para abastecer a demanda de sua carne, muito apreciada nos centros urbanos do Amazonas. Já existem em Manaus-AM restaurantes credenciados pelo Ibama para servirem pratos à base de tartaruga, e o sucesso dessa atividade pode ser geradora de emprego para o homem rural.

De acordo com Silva Neto (1998), os resultados da avaliação do rendimento de carcaça de 71 espécimes de $P$. expansa com peso médio de $2,53 \mathrm{~kg}$ para abate comercial apresentaram os seguintes valores porcentuais: carcaça (carne com o tecido ósseo dos membros), 30,44 $\pm 5,10 \%$; comercial (carcaça, carapaça, gordura, fígado e coração), 56,02 $\pm 8,61 \%$; carapaça, 20,68 $\pm 1,05 \%$ e gordura $8,20 \% \pm 3,19$. Para o autor citado, é enfatizada a importância de se comercializar o produto com a carapaça acompanhando a carcaça, visando melhor controle de sua procedência. Além disso, existe a dificuldade de separar essas duas peças, pois a coluna vertebral é fundida à carapaça.

Em análises de rendimento de carcaça em cinco espécimes de $P$. expansa, Duarte (1998) constatou os seguintes valores porcentuais em relação ao peso corporal médio de 2,66 kg: para carcaça (dianteiro, traseiro e lombo), 32,83 $\pm 9,09 \%$; para vísceras totais, $7,96 \pm 1,31 \%$ e para o fígado, $1,48 \pm 0,29 \%$. Esse autor informou que animais de maior tamanho e peso apresentam maior rendimento de carcaça do que animais de categorias menores.

Pádua et al. (1983) procederam à análise da carne de uma tartaruga-da-amazônia de $12 \mathrm{~kg}$ apre- endida e constataram que o teor de proteína foi de $84,68 \%$ na matéria seca, superior ao das carnes de diversos animais de criações tradicionais, a exemplo do frango, bovinos, suínos, ovinos ou mesmo do leite, iogurte e ovos de galinha. A concentração de aminoácidos também foi analisada, encontrando-se em 100 gramas de proteína: lisina, 7,70 g; histidina, 2,21 g; arginina, 4,11 g; treonina, 3,91 g; ácido glutâmico, $16,56 \mathrm{~g}$; glicina, $5,80 \mathrm{~g}$; valina, $6,25 \mathrm{~g}$; isoleucina, 5,41 g; tirosina, $10,64 \mathrm{~g}$ e metionina $5,32 \mathrm{~g}$.

Gaspar \& Rangel Filho (2000) apresentaram como composição bromatológica da carne da tartaruga $78,80 \%$ de umidade, $1,83 \%$ de lipídios e $17,39 \%$ de proteína bruta. Informaram, ainda, que a carne é magra e com baixo valor calórico $(86,03 \mathrm{kcal} / 100 \mathrm{~g})$.

Reis \& De Marco (2000) realizaram análises da composição bromatológica de seis espécimes de tartaruga-da-amazônia, com pesos entre 82,00 e 637,00 g, oriundos de cativeiro. Os resultados médios encontrados foram: para a matéria seca, 34,90\%; para proteína bruta, $57,80 \%$; e para o extrato etéreo, $8,80 \%$. Esses porcentuais aumentaram proporcionalmente em relação ao peso do animal, sugerindo que podem ocorrer variações segundo o tamanho corporal, a idade e a qualidade da dieta oferecida.

$\mathrm{O}$ efetivo enquadramento da tartaruga-daamazônia como fonte protéica disponível comercialmente só será realidade à medida que houver maior conhecimento científico, relacionado à sua biologia. Pouco se conhece sobre o rendimento de carcaça, o que sugere a necessidade de se conduzirem pesquisas que possam corroborar e/ou produzir novas informações visando contribuir para a criação da tartaruga em cativeiro. Assim, esse trabalho teve como objetivo avaliar o rendimento e composição de carcaça de Podocnemis expansa, com idades entre 23 e 29 meses, mantidos em criadouros comerciais.

\section{Material e Métodos}

O experimento foi conduzido no período de novembro de 1999 a julho de 2000 , em duas etapas. A primeira foi realizada no município de Diorama, Goiás, localizado na região oeste do Estado, onde se acompanhou o crescimento de Podocnemis expansa em oito criadouros comerciais licenciados pelo Ibama. $\mathrm{Na}$ segunda etapa, realizou-se a avaliação do rendimento e da composição química das carcaças. Essa fase foi conduzida nos Laboratórios de Medicina Veterinária Preventiva e de Nutrição Animal da Escola de

\footnotetext{
R. Bras. Zootec., v.32, n.1, p.1-9, 2003
} 
Veterinária da Universidade Federal de Goiás.

A colheita dos dados biométricos foi conduzida no período de 15 de novembro de 1999 a 22 de maio de 2000, correspondendo ao intervalo entre o $23^{\circ}$ e o $29^{\circ}$ meses de idade. Foi tomada uma amostra mensal, aleatória, de 100 animais, capturados por rede de arrasto e retiradas suas medidas biométricas. Os procedimentos para realização das medidas biométricas foram aqueles utilizados pelo CENAQUA (1999). Foi medido o comprimento retilíneo da carapaça em milímetros, com o auxílio de paquímetro de metal, com capacidade de $200 \mathrm{~mm}$, além de paquímetro de madeira com capacidade de $50 \mathrm{~cm}$ e precisão de $1 \mathrm{~cm}$, conforme o estágio de crescimento do animal. As medidas foram tomadas entre a extremidade anterior do contato dos primeiros escudos marginais até o ponto mais posterior da sutura dos escudos supracaudais (Figura 1). O peso foi obtido utilizandose balança eletrônica com capacidade de $3 \mathrm{~kg}$ e precisão de $1 \mathrm{~g}$, e calcularam-se o ganho de peso e comprimento da carapaça, nos diferentes períodos.

Para obtenção dos dados e cálculos do rendimento de carcaça, foram selecionadas cinco tartarugas, de cada criadouro, com pesos próximos aos valores médios registrados nas biometrias do $23^{\circ}, 25^{\circ}$, $27^{\circ}$ e $29^{\circ}$ mês de idade, perfazendo um total de quatro colheitas com 20 exemplares de cada criadouro. Procedeu-se à pesagem dos animais e mediu-se o comprimento retilíneo da carapaça, em milímetros. Em seguida eles foram identificados e transportados para o Departamento de Medicina Veterinária Preventiva da Escola de Veterinária da UFG (Goiânia - GO), visando ao abate e à avaliação do rendimento de carcaça.

$\mathrm{O}$ abate foi realizado conforme os procedimentos sugeridos por Silva Neto (1998). Para insensibilização dos animais, estes foram colocados em um recipiente, contendo água e gelo a uma temperatura em torno de $5^{\circ} \mathrm{C}$, durante 20 minutos. Para o abate foi realizada a secção da cabeça. Após a retirada do plastrão com o auxílio de uma serra giratória elétrica, foi efetuada manualmente a retirada das vísceras do trato digestório, fígado, pâncreas, gordura, baço, pulmões, aparelho excretor, órgãos reprodutores, carcaça e o conjunto carapaça + carcaça. A carcaça compreende toda a musculatura estriada esquelética, juntamente com o tecido ósseo dos membros e das vértebras cervicais, lombares e caudais, não sendo retirada a pele das patas. A carapaça + carcaça corresponde ao conjunto comercial para a comercialização sugerido por Silva Neto (1998), devido à dificuldade de separar essas

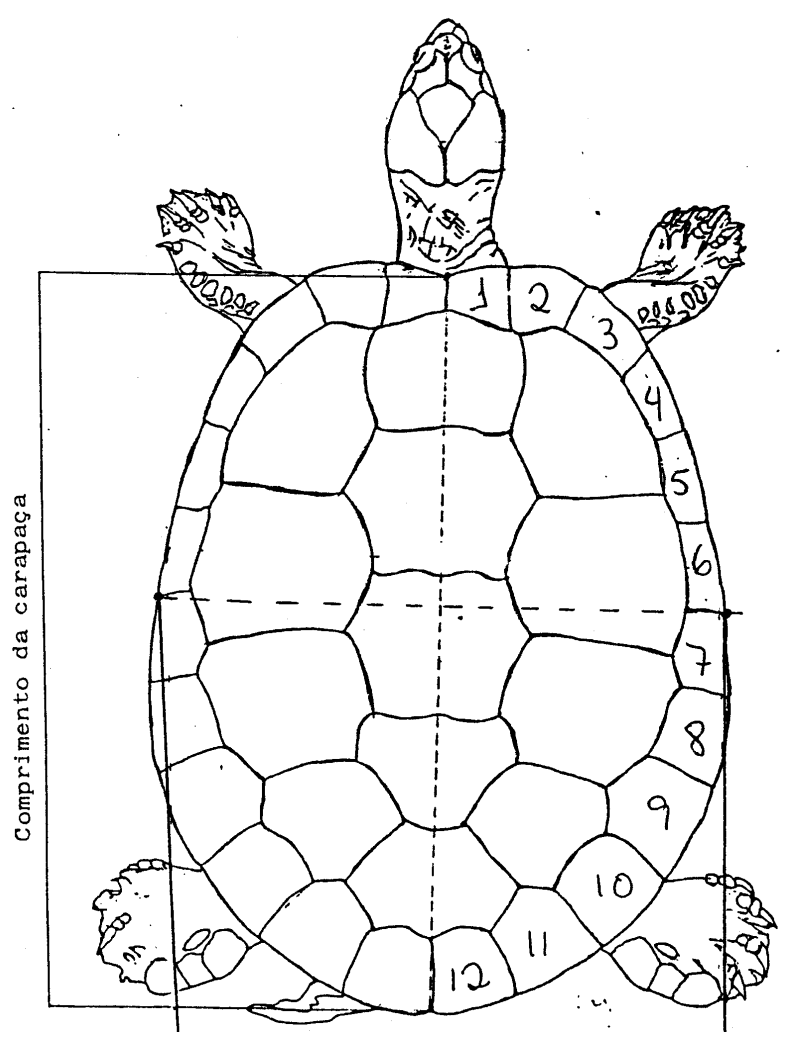

Figura 1 - Representação da medida biométrica do comprimento retilíneo da carapaça em Podocnemis expansa (tartaruga-da-amazônia).

Figure 1 - Rectilinear biometric measure of the carapace length of Podocnemis expansa (tartaruga-daamazônia).

duas peças, e para controle da origem do produto.

Para o cálculo de rendimento de carcaça e dos órgãos, tomou-se como base o peso vivo individual de cinco tartarugas, em cada idade estudada. As variáveis foram analisadas para cada idade, e os valores obtidos foram tabulados e apresentados em porcentagem: peso da carcaça com vísceras (coração, fígado, baço, pulmões, trato digestório, aparelho excretor e órgãos reprodutores); peso da carcaça sem vísceras; peso total das vísceras (coração, fígado, baço, pulmões, trato digestório, aparelho excretor e órgãos reprodutores); peso da gordura e peso do fígado.

Ao final do experimento, as carcaças de cada animal obtidas no $29^{\circ}$ mês, por criadouro, foram identificadas e acondicionadas em sacos plásticos e congeladas para posterior processamento. Após serem retiradas da câmara fria e descongeladas, as carcaças foram trituradas individualmente, utilizan-

R. Bras. Zootec., v.32, n.1, p.1-9, 2003 
do-se moedor de carne e, após a homogeneização, foi tomada uma alíquota em torno de $80 \%$ do peso, para cada amostra, para utilização nas análises de proteína bruta (PB), extrato etéreo (EE) e matéria seca (MS). Para tanto, seguiram-se as metodologias analíticas propostas por Silva (1990). As análises foram realizadas em triplicata, para cada amostra, no Laboratório de Nutrição Animal do Departamento de Produção Animal da Escola de Veterinária da UFG, em Goiânia. A proteína bruta e o extrato etéreo foram calculados com base na matéria úmida (MN) e na matéria seca $(\mathrm{MS})$ a $105^{\circ} \mathrm{C}$. Foi calculada também a relação entre proteína bruta e o extrato etéreo com base na matéria úmida.

As análises estatísticas foram realizadas de acordo com o recomendado por Sampaio (1998), utilizando-se o programa ESTAT (Sistema de Análises Estatísticas) desenvolvido pelo Departamento de Ciências Exatas da Universidade Estadual Paulista/Faculdade de Ciências Agrárias e Veterinárias, Campus de
Jaboticabal. Foi aplicado o teste Duncan, a 5\% de probabilidade, para comparação de médias. Para tanto, os dados porcentuais de carcaça com vísceras, carcaça sem vísceras, carapaça + carcaça, gordura e fígado foram transformados em arco seno vx.

Objetivando verificar a potência das relações entre o peso médio corporal e o peso dos diversos dados de rendimento da carcaça, foram analisadas as correlações dessas variáveis por meio de análise de regressão múltipla. Para esses cálculos foram utilizados os valores médios dos pesos no período de 23 a 29 meses, no programa computacional Statistica (Stat Soft, 1996).

\section{Resultados e Discussão}

Analisados os valores médios de rendimento de carcaça com vísceras, sem vísceras e o conjunto comercial (carapaça + carcaça) nos oito criadouros, entre 23 e 29 meses de idade (Tabelas 1 e 2), comparados pelo teste Duncan, observou-se diferen-

Tabela 1 - Valores médios de rendimento da carcaça com e sem vísceras de Podocnemis expansa com idade entre 23 e 29 meses, provenientes de criadouros comerciais $(n=5)$

Table 1 - Mean carcass yield values for carcass with and without viscera of Podocnemis expansa from 23 to 29 months of age, from commercial flocks $(n=5)$

\begin{tabular}{|c|c|c|c|c|}
\hline \multirow[t]{2}{*}{$\begin{array}{l}\text { Criadouros } \\
\text { Commercial flocks }\end{array}$} & \multicolumn{4}{|c|}{$\begin{array}{l}\text { Idade (meses) } \\
\text { Age (months) }\end{array}$} \\
\hline & 23 & 25 & 27 & 29 \\
\hline & \multicolumn{4}{|c|}{$\begin{array}{l}\text { Rendimento da carcaça com vísceras (\%) } \\
\text { Yield of the carcass plus viscera }(\%)\end{array}$} \\
\hline Faz. Vale da Serra & $44,93^{\mathrm{b}}$ & $48,40^{\mathrm{ab}}$ & $49,86^{\mathrm{ab}}$ & $53,02^{\mathrm{a}}$ \\
\hline Pró-Fauna & $49,04^{\mathrm{b}}$ & $48,21^{\mathrm{ab}}$ & $53,38^{a}$ & $51,87^{\mathrm{ab}}$ \\
\hline Agrotec & $51,10^{\mathrm{a}}$ & $49,92^{\mathrm{a}}$ & $48,39^{\mathrm{ab}}$ & $48,08^{\mathrm{bc}}$ \\
\hline Faz. São Romão & $43,45^{\mathrm{b}}$ & $48,92^{\mathrm{ab}}$ & $39,66^{\mathrm{c}}$ & $46,45^{\mathrm{c}}$ \\
\hline Faz. Campo Redondo & $46,36^{\mathrm{b}}$ & $48,12^{\mathrm{ab}}$ & $52,48^{\mathrm{a}}$ & $49,11^{\mathrm{abc}}$ \\
\hline Faz. Lambari & $48,28^{\mathrm{b}}$ & $46,24^{\mathrm{b}}$ & $48,87^{\mathrm{ab}}$ & $46,75^{\mathrm{c}}$ \\
\hline Faz. Rios dos Bois & $45,78^{\mathrm{b}}$ & $40,89^{\mathrm{c}}$ & $46,59^{b}$ & $40,86^{\mathrm{d}}$ \\
\hline Faz. Alcantilhado & $42,55^{\mathrm{b}}$ & $46,39^{\mathrm{b}}$ & $38,79^{\mathrm{c}}$ & $37,54^{\mathrm{d}}$ \\
\hline Média (Mean) & 46,44 & 47,13 & 47,18 & 46,71 \\
\hline \multirow[t]{2}{*}{ CV $(\%)$} & 5,90 & 2,78 & 4,36 & 4,71 \\
\hline & \multicolumn{4}{|c|}{$\begin{array}{l}\text { Rendimento da carcaça sem vísceras }(\%) \\
\text { Yield of the carcass without viscera }(\%)\end{array}$} \\
\hline Faz. Vale da Serra & $30,40^{\mathrm{a}}$ & $30,80^{\mathrm{a}}$ & $33,92^{\mathrm{a}}$ & $36,26^{\mathrm{a}}$ \\
\hline Pró-Fauna & $30,96^{\mathrm{a}}$ & $30,01^{\mathrm{ab}}$ & $32,60^{\mathrm{ab}}$ & $36,99^{a}$ \\
\hline Agrotec & $30,96^{\mathrm{a}}$ & $29,98^{\mathrm{ab}}$ & $30,41^{\mathrm{b}}$ & $30,39^{c}$ \\
\hline Faz. São Romão & $30,23^{\mathrm{a}}$ & $28,07^{\mathrm{bc}}$ & $26,54^{\mathrm{c}}$ & $27,34^{\mathrm{d}}$ \\
\hline Faz. Campo Redondo & $29,10^{\mathrm{ab}}$ & $27,17^{\mathrm{c}}$ & $31,10^{\mathrm{b}}$ & $35,43^{\mathrm{ab}}$ \\
\hline Faz. Lambari & $29,53^{\mathrm{a}}$ & $28,84^{\mathrm{abc}}$ & $31,09^{b}$ & $32,76^{\mathrm{bc}}$ \\
\hline Faz. Rios dos Bois & $26,22^{\mathrm{b}}$ & $24,31^{\mathrm{d}}$ & $26,25^{\mathrm{c}}$ & $26,96^{\mathrm{d}}$ \\
\hline Faz. Alcantilhado & $28,95^{\mathrm{ab}}$ & $28,30^{\mathrm{abc}}$ & $27,97^{\mathrm{c}}$ & $26,71^{\mathrm{d}}$ \\
\hline Média (Mean) & 29,55 & 28,44 & 29,89 & 31,60 \\
\hline $\mathrm{CV}(\%)$ & 4,17 & 3,45 & 3,17 & 4,01 \\
\hline
\end{tabular}

Médias seguidas por letras iguais, na mesma coluna, não diferem entre si pelo teste Duncan $(P>0,05)$; $C V=$ coeficiente de variação. Means indicated by the same letters, in the same column, do not differ by Duncan range test $(P>.05)$; CV $=$ coefficient of variation.

R. Bras. Zootec., v.32, n.1, p.1-9, 2003 
Tabela 2 - Valores médios de rendimento do conjunto comercial (carapaça + carcaça), de Podocnemis expansa, entre 23 e 29 meses de idade, provenientes de criadouros comerciais $(n=5)$

Table 2 - Mean yield values for the whole commercial stuff (carapace + carcass) of Podocnemis expansa from 23 to 29 months of age, from commercial flocks $(n=5)$

\begin{tabular}{|c|c|c|c|c|}
\hline \multirow[t]{2}{*}{$\begin{array}{l}\text { Criadouros } \\
\text { Commercial flocks }\end{array}$} & \multicolumn{4}{|c|}{$\begin{array}{l}\text { Idade (meses) } \\
\text { Age (months) }\end{array}$} \\
\hline & 23 & 25 & 27 & 29 \\
\hline & \multicolumn{4}{|c|}{$\begin{array}{c}\text { Rendimento de carcaça }+ \text { carapaça } \\
\text { Yield of the carcass }+ \text { carapace }\end{array}$} \\
\hline Faz. Vale da Serra & $57,72^{\mathrm{a}}$ & $50,22^{\mathrm{a}}$ & $53,60^{\mathrm{a}}$ & $54,90^{\mathrm{a}}$ \\
\hline Pró-Fauna & $55,85^{\mathrm{a}}$ & $49,22^{\mathrm{ab}}$ & $52,10^{\mathrm{ab}}$ & $56,39^{\mathrm{a}}$ \\
\hline Agrotec & $53,72^{\mathrm{a}}$ & $49,55^{\mathrm{ab}}$ & $48,90^{\mathrm{bc}}$ & $50,22^{\mathrm{b}}$ \\
\hline Faz. São Romão & $48,60^{\mathrm{ab}}$ & $45,63^{\mathrm{c}}$ & $47,93^{\mathrm{bc}}$ & $47,36^{\text {bc }}$ \\
\hline Faz. Campo Redondo & $43,59^{b}$ & $45,43^{\mathrm{c}}$ & $49,17^{\mathrm{bc}}$ & $53,63^{\text {bc }}$ \\
\hline Faz. Lambari & $50,85^{\mathrm{ab}}$ & $47,98^{b}$ & $48,87^{\mathrm{bc}}$ & $53,89^{\mathrm{a}}$ \\
\hline Faz. Rios dos Bois & $48,57^{\mathrm{ab}}$ & $43,05^{\mathrm{d}}$ & $45,36^{c}$ & $46,40^{\mathrm{c}}$ \\
\hline Faz. Alcantilhado & $50,36^{\mathrm{ab}}$ & $45,70^{\mathrm{c}}$ & $47,69^{\mathrm{c}}$ & $46,65^{\mathrm{c}}$ \\
\hline Média (Mean) & 50,95 & 47,10 & 49,09 & 51,18 \\
\hline $\mathrm{CV}(\%)$ & 6,52 & 2,07 & 3,74 & 3,02 \\
\hline
\end{tabular}

Médias seguidas por letras iguais, na mesma coluna, não diferem entre si pelo teste Duncan $(P>0,05)$; CV = coeficiente de variação. Means indicated by the same letters, in the same column, do not differ by Duncan range test $(P>.05) ; C V=$ coefficient of variation.

ça $(\mathrm{P}<0,05)$ para quase todos os criadouros, de acordo com os valores médios do comprimento da carapaça e do peso corporal (Tabela 3).

Para a carcaça com vísceras, constituída por vísceras comestíveis (fígado e coração), não comestíveis (baço, pulmões, trato digestório, aparelho excretor e órgãos reprodutores), foram encontrados valores médios de $46,87 \%$ para animais com peso médio de $621,35 \mathrm{~g}$ (Tabela 1). Resultados semelhantes foram encontrados por Silva Neto (1998), com $45,79 \%$ de rendimento para carcaças com vísceras em tartarugas com peso médio de $2,53 \mathrm{~kg}$.

Os valores médios de rendimento obtidos para a carcaça sem vísceras (carne com ossos dos membros e das vértebras cervicais, lombares e caudais) apresentaram valores significativos $(\mathrm{P}<0,05)$ entre os criadouros, principalmente a partir do $25^{\circ}$ mês, observando-se que o rendimento médio foi de $29,87 \%$ (Tabela 1 ). Dados semelhantes aos encontrados neste experimento foram apresentados por Silva Neto (1998), que registrou um rendimento da ordem de $30,44 \%$ para animais com peso médio de 2,53 kg. Este autor informou, ainda, que esse rendimento responde à necessidade de mercado, pois um animal de $1,50 \mathrm{~kg}$ de peso vivo deve conferir aproximadamente $450 \mathrm{~g}$ de carne com ossos, quantidade suficiente para o consumo de duas pessoas em restaurantes. Duarte (1998) encontrou rendimento médio de carcaça de $32,83 \%$, para animais com $2,66 \mathrm{~kg}$, ressaltando que aqueles de maior tamanho e peso apresentaram maior rendimento.

O conjunto comercial (carapaça + carcaça) apresentou rendimento médio de $49,58 \%$, desconsideradas as vísceras comestíveis e a gordura (Tabela 2). Os valores obtidos por Silva Neto (1998) foram da ordem de $56,02 \%$, porém consideraram-se o fígado, o coração e a gordura como partes desse conjunto. $\mathrm{O}$ autor enfatizou a necessidade de a carcaça vir acompanhada da carapaça com o lacre de identificação do Ibama, o que garante que aquele produto é oriundo de um criadouro devidamente registrado e autorizado para a comercialização.

A relação porcentual entre a gordura depositada e o peso vivo (Tabela 4) apresentou médias diferentes $(\mathrm{P}<0,05)$ para quase todos os criadouros e períodos. Constatou-se, no criadouro Vale da Serra, depósito de gordura $(10,07 \%)$ duas vezes maior que a média encontrada nos animais dos outros criadouros (5,00\%). Silva Neto (1998) encontrou um porcentual de $8,20 \%$, como valor médio para essa espécie, superior à média de $5 \%$, obtida nesse estudo. Observou-se, também, que os animais dos criadouros São Romão (3,48\%), Rios dos Bois (3,65\%) e Alcantilhado $(4,19 \%)$ apresentaram os mais baixos níveis de gordura corporal, provavelmente resultado do manejo alimentar a que foram submetidos nessa fase de crescimento, com grãos, frutas e verduras.

Os valores médios dos pesos das vísceras obtidos nas tartarugas (Tabela 5) foram diferentes entre os 
Tabela 3 - Valores médios do comprimento retilíneo da carapaça $(\mathrm{mm})$ e peso corporal $(\mathrm{g})$ de Podocnemis expansa com idade entre 23 e 29 meses, de criadouros comerciais $(n=100)$

Table 3 - Mean value rectilinear carapace length $(\mathrm{mm})$ and body weight $(\mathrm{g})$ of Podocnemis expansa from 23 to 29 months of age, from comercial flocks $(n=100)$

\begin{tabular}{|c|c|c|c|c|}
\hline \multirow[t]{2}{*}{$\begin{array}{l}\text { Criadouros } \\
\text { Commercial flocks }\end{array}$} & \multicolumn{4}{|c|}{$\begin{array}{l}\text { Idade (meses) } \\
\text { Age (months) }\end{array}$} \\
\hline & 23 & 25 & 27 & 29 \\
\hline & \multicolumn{4}{|c|}{$\begin{array}{l}\text { Comprimento médio da carapaça }(\mathrm{mm}) \\
\text { Mean rectileneal carapace lenght }(\mathrm{mm})\end{array}$} \\
\hline Faz. Vale da Serra & $180,80^{\mathrm{a}}$ & $203,20^{\mathrm{a}}$ & $218,00^{\mathrm{a}}$ & $211,40^{\mathrm{a}}$ \\
\hline Pró-Fauna & $167,80^{\mathrm{bc}}$ & $179,40^{c}$ & $191,20^{\mathrm{b}}$ & $188,00^{\mathrm{b}}$ \\
\hline Agrotec & $164,20^{c}$ & $162,20^{\mathrm{d}}$ & $162,80^{\mathrm{de}}$ & $164,80^{\mathrm{d}}$ \\
\hline Faz. São Romão & $171,40^{\mathrm{b}}$ & $188,20^{\mathrm{b}}$ & $172,60^{c}$ & $175,80^{\circ}$ \\
\hline Faz. Campo Redondo & $146,40^{\mathrm{e}}$ & $153,60^{\mathrm{e}}$ & $159,20^{\mathrm{ef}}$ & $158,60^{\mathrm{d}}$ \\
\hline Faz. Lambari & $154,00^{\mathrm{d}}$ & $158,80^{\text {de }}$ & $166,80^{\mathrm{d}}$ & $164,60^{\circ}$ \\
\hline Faz. Rios dos Bois & $147,80^{\mathrm{de}}$ & $146,80^{\mathrm{f}}$ & $155,20^{\mathrm{f}}$ & $147,20^{\mathrm{e}}$ \\
\hline Faz. Alcantilhado & $128,40^{\mathrm{f}}$ & $125,60^{\mathrm{g}}$ & $124,40^{\mathrm{g}}$ & $121,20^{\mathrm{f}}$ \\
\hline Média (Mean) & 157,60 & 164,72 & 167,51 & 166,45 \\
\hline \multirow[t]{2}{*}{$\mathrm{CV}(\%)$} & 3,30 & 2,73 & 2,55 & 2,96 \\
\hline & \multicolumn{4}{|c|}{$\begin{array}{l}\text { Peso corporal médio }(\mathrm{g}) \\
\text { Mean body weight }(\mathrm{g})\end{array}$} \\
\hline Faz. Vale da Serra & $774,00^{\mathrm{a}}$ & $1026,00^{\mathrm{a}}$ & $1216,75^{\mathrm{a}}$ & $1195,20^{\mathrm{a}}$ \\
\hline Pró-Fauna & $585,40^{\mathrm{b}}$ & $742,60^{\mathrm{b}}$ & $849,00^{\mathrm{b}}$ & $799,80^{b}$ \\
\hline Agrotec & $531,60^{c}$ & $529,60^{c}$ & $495,00^{\text {fg }}$ & $519,20^{\mathrm{f}}$ \\
\hline Faz. São Romão & $609,20^{\mathrm{b}}$ & $771,20^{\mathrm{b}}$ & $590,40^{\mathrm{e}}$ & $628,20^{\circ}$ \\
\hline Faz. Campo Redondo & $468,60^{\mathrm{d}}$ & $536,80^{c}$ & $626,20^{c}$ & $607,00^{\circ}$ \\
\hline Faz. Lambari & $477,80^{\mathrm{d}}$ & $539,00^{c}$ & $591,00^{\text {de }}$ & $565,80^{\mathrm{c}}$ \\
\hline Faz. Rios dos Bois & $434,60^{e}$ & $427,00^{d}$ & $481,80^{\mathrm{g}}$ & $421,80^{\circ}$ \\
\hline Faz. Alcantilhado & $287,60^{f}$ & $264,40^{\mathrm{e}}$ & $254,40^{\mathrm{h}}$ & $233,80^{\mathrm{h}}$ \\
\hline Média (Mean) & 521,10 & 604,57 & 623,23 & 621,35 \\
\hline $\mathrm{CV}$ & 4,27 & 4,56 & 3,64 & 2,21 \\
\hline
\end{tabular}

Médias seguidas por letras iguais, na mesma coluna, não diferem entre si pelo teste Duncan $(P>0,05)$; CV = coeficiente de variação. Means indicated by the same letters, in the same column, do not differ by Duncan range test ( $P>.05)$; $C V=$ coefficient of variation.

Tabela 4 - Porcentual da gordura em relação ao peso corporal médio de Podocnemis expansa, entre 23 e 29 meses de idade, provenientes de criadouros comerciais $(n=5)$

Table 4 - Fat percentage in relation to the mean body weight of Podocnemis expansa from 23 to 29 months of age, from commercial flocks $(n=5)$

\begin{tabular}{|c|c|c|c|c|}
\hline \multirow[t]{2}{*}{$\begin{array}{l}\text { Criadouros } \\
\text { Commercial flocks }\end{array}$} & \multicolumn{4}{|c|}{$\begin{array}{c}\text { Idade (meses) } \\
\text { Age (months) }\end{array}$} \\
\hline & 23 & 25 & 27 & 29 \\
\hline & \multicolumn{4}{|c|}{$\begin{array}{c}\text { Gordura }(\%) \\
\text { Fat }(\%)\end{array}$} \\
\hline Faz. Vale da Serra & $11,35^{\mathrm{a}}$ & $10,12^{\mathrm{a}}$ & $9,60^{\mathrm{a}}$ & $9,22^{\mathrm{a}}$ \\
\hline Pró-Fauna & $3,14^{\mathrm{c}}$ & $4,54^{\mathrm{bc}}$ & $3,21^{\mathrm{d}}$ & $4,20^{b c}$ \\
\hline Agrotec & $4,47^{\mathrm{bc}}$ & $4,30^{\mathrm{bc}}$ & $2,29^{\mathrm{de}}$ & $3,38^{\mathrm{c}}$ \\
\hline Faz. São Romão & $5,49^{\text {bc }}$ & $4,62^{\mathrm{bc}}$ & $0,79^{\mathrm{e}}$ & $3,02^{\mathrm{c}}$ \\
\hline Faz. Campo Redondo & $6,23^{\mathrm{b}}$ & $5,77^{b}$ & $5,61^{b c}$ & $6,08^{\mathrm{b}}$ \\
\hline Faz. Lambari & $4,55^{\mathrm{bc}}$ & $5,02^{\mathrm{bc}}$ & $5,85^{\mathrm{b}}$ & $6,36^{\mathrm{b}}$ \\
\hline Faz. Rios dos Bois & $4,35^{\mathrm{bc}}$ & $3,36^{\mathrm{c}}$ & $5,10^{\mathrm{bc}}$ & $2,25^{\mathrm{bc}}$ \\
\hline Faz. Alcantilhado & $6,78^{b}$ & $5,43^{\mathrm{b}}$ & $3,66^{\mathrm{cd}}$ & $0,88^{\mathrm{d}}$ \\
\hline Média (Mean) & 5,79 & 5,40 & 4,38 & 4,42 \\
\hline $\mathrm{CV}(\%)$ & 18,36 & 12,62 & 12,44 & 19,57 \\
\hline
\end{tabular}

Médias seguidas por letras iguais, na mesma coluna, não diferem entre si pelo teste Duncan $(P>0,05)$; $C V=$ coeficiente de variação. Means indicated by the same letters, in the same column, do not differ by Duncan range test ( $P>.05) ; C V=$ coefficient of variation. 
Tabela 5 - Porcentual das vísceras totais em relação ao peso corporal médio de Podocnemis expansa, entre 23 e 29 meses de idade, provenientes de criadouros comerciais $(n=5)$

Table 5 - Total viscera percentage in relation to the mean body weight of Podocnemis expansa from 23 to 29 months of age, from commercial flocks $(n=5)$

\begin{tabular}{|c|c|c|c|c|}
\hline \multirow[t]{2}{*}{$\begin{array}{l}\text { Criadouros } \\
\text { Commercial flocks }\end{array}$} & \multicolumn{4}{|c|}{$\begin{array}{c}\text { Idade (meses) } \\
\text { Age (months) }\end{array}$} \\
\hline & 23 & 25 & 27 & 29 \\
\hline & \multicolumn{4}{|c|}{$\begin{array}{c}\text { Vísceras (\%) } \\
\text { Viscera (\%) }\end{array}$} \\
\hline Faz. Vale da Serra & $14,53^{\mathrm{bcd}}$ & $17,59^{\mathrm{ab}}$ & $15,94^{\mathrm{ab}}$ & $16,79^{\mathrm{abc}}$ \\
\hline Pró-Fauna & $18,08^{\mathrm{ab}}$ & $18,18^{\mathrm{ab}}$ & $20,79^{a}$ & $14,80^{\mathrm{bc}}$ \\
\hline Agrotec & $20,13^{\mathrm{a}}$ & $19,93^{\mathrm{ab}}$ & $17,97^{\mathrm{a}}$ & $17,68^{\mathrm{ab}}$ \\
\hline Faz. São Romão & $13,22^{\mathrm{d}}$ & $20,85^{\mathrm{a}}$ & $13,16^{\mathrm{bc}}$ & $19,10^{\mathrm{a}}$ \\
\hline Faz. Campo Redondo & $17,25^{\mathrm{abc}}$ & $21,15^{\mathrm{a}}$ & $21,38^{\mathrm{a}}$ & $13,68^{\mathrm{cd}}$ \\
\hline Faz. Lambari & $18,75^{\mathrm{a}}$ & $17,39^{\mathrm{ab}}$ & $17,78^{\mathrm{a}}$ & $13,98^{\mathrm{bcd}}$ \\
\hline Faz. Rios dos Bois & $19,55^{\mathrm{a}}$ & $16,57^{\mathrm{b}}$ & $20,34^{\mathrm{a}}$ & $13,90^{\text {bcd }}$ \\
\hline Faz. Alcantilhado & $13,60^{\mathrm{cd}}$ & $10,59^{c}$ & $10,59^{c}$ & $10,82^{\mathrm{d}}$ \\
\hline Média (Mean) & 16,89 & 17,78 & 17,28 & 15,09 \\
\hline $\mathrm{CV}(\%)$ & 9,70 & 7,79 & 9,96 & 9,65 \\
\hline
\end{tabular}

Médias seguidas por letras iguais, na mesma coluna, não diferem entre si pelo teste Duncan $(P>0,05)$; $C V=$ coeficiente de variação. Means indicated by the same letters, in the same column, do not differ by Duncan range test $(P>.05) ; C V=$ coefficient of variation.

criadouros $(\mathrm{P}<0,05)$, com média geral de $16,76 \%$, e tiveram influência principalmente da alimentação a que foram submetidas. Nos criadouros Agrotec, São Romão, Rio dos Bois, que utilizaram dieta à base de milho, foram encontrados, em todo trato gastrointestinal, grãos inteiros de milho e até pequenas pedras, indicando o não-aproveitamento do alimento e, possivelmente, superestimando o peso corporal.

Para esse parâmetro, Silva Neto (1998) obteve média de $15,52 \%$, para as vísceras coração, fígado, baço, pulmões, trato digestório, aparelho excretor e órgãos reprodutores, resultados próximos aos encontrados nesse estudo.

Os pesos médios do fígado em exemplares com idades de 23 a 29 meses (Tabela 6) foram diferentes entre os criadouros $(\mathrm{P}<0,05)$ em todos os períodos. Nesse estudo, verificou-se que o fígado é a glândula mais pesada correspondendo a $2,90 \%$ do peso corporal, corroborando com as descrições de Ashley (1969).

A composição química da carcaça em matéria seca (MS), proteína bruta (PB), extrato etéreo (EE) e a relação $\mathrm{PB} / \mathrm{EE}$ está apresentada na Tabela 7 . Comparando-se as médias para MS entre os criadouros, estas mostraram-se diferentes $(\mathrm{P}<0,05)$, com uma média de $22,30 \%$. Para PB foram encontrados os índices de $77,98 \%$ na matéria seca e $17,38 \%$ na matéria úmida, constatando-se diferenças não significativas $(\mathrm{P}>0,05)$ com base na MS. Os animais apresentaram baixa porcentagem de extrato etéreo, com médias diferentes entre os criadouros $(\mathrm{P}<0,05)$, sendo que na MU apresentou média de $1,09 \%$ e na MS de 4,79\%. Sobre esses parâmetros, Pádua et al. (1983) encontraram teor de 84,68\% para PB de uma tartaruga apreendida na natureza. Análises realizadas por Gaspar \& Rangel Filho (2000) mostraram que em tartarugas provenientes de cativeiro os valores foram de $78,80 \%$ para matéria seca, $17,39 \%$ para proteína bruta e $1,83 \%$ para extrato etéreo, enfatizando que estas possuem carne magra, de coloração semelhante à carne de frango, e baixo valor calórico $(86,03 \mathrm{kcal} / 100 \mathrm{~g})$.

Reis \& De Marco (2000), com exemplares de $P$. expansa provenientes de criadouros, revelaram índices de matéria seca de $34,00 \%$, proteína bruta de $57,00 \%$ e, para o extrato etéreo na matéria úmida, $8,80 \%$, valor bastante superior ao encontrado nesse estudo e na literatura consultada. Os autores verificaram que esses porcentuais foram proporcionais à idade do animal, sugerindo que essas variações podem ocorrer devido ao tamanho corporal, idade e qualidade da dieta oferecida.

Na Tabela 8, observa-se que o peso corporal está correlacionado positivamente com o rendimento de carcaça $(r=0,97)$, gordura $(r=0,81)$ e vísceras $(r=0,86)$. 
Tabela 6 - Percentuais dos pesos do fígado em relação ao peso corporal médio de Podocnemis expansa entre 23 e 29 meses de idade, provenientes de criadouros comerciais $(n=5)$

Table 6 - Liver percentage weights in relation to the mean body weight of Podocnemis expansa from 23 to 29 months of age, from commercial flocks $(n=5)$

\begin{tabular}{|c|c|c|c|c|}
\hline \multirow[t]{2}{*}{$\begin{array}{l}\text { Criadouros } \\
\text { Commercial flocks }\end{array}$} & \multicolumn{4}{|c|}{$\begin{array}{l}\text { Idade (meses) } \\
\text { Age (months) }\end{array}$} \\
\hline & 23 & 25 & 27 & 29 \\
\hline & \multicolumn{4}{|c|}{$\begin{array}{c}\text { Fígado (\%) } \\
\text { Liver (\%) }\end{array}$} \\
\hline Faz. Vale da Serra & $3,09^{\mathrm{ab}}$ & $3,60^{\mathrm{a}}$ & $4,10^{\mathrm{a}}$ & $4,66^{\mathrm{a}}$ \\
\hline Pró-Fauna & $2,57^{\text {bcd }}$ & $2,90^{\mathrm{b}}$ & $3,89^{\mathrm{ab}}$ & $4,41^{\mathrm{a}}$ \\
\hline Agrotec & $2,86^{\mathrm{abc}}$ & $2,85^{\mathrm{b}}$ & $3,27^{\mathrm{cd}}$ & $3,84^{b}$ \\
\hline Faz. São Romão & $2,15^{\mathrm{d}}$ & $2,18^{\mathrm{c}}$ & $1,86^{\mathrm{f}}$ & $2,38^{\mathrm{d}}$ \\
\hline Faz. Campo Redondo & $2,03^{\mathrm{d}}$ & $2,63^{\mathrm{b}}$ & $2,79^{\mathrm{e}}$ & $3,91^{\mathrm{b}}$ \\
\hline Faz. Lambari & $2,31^{\mathrm{cd}}$ & $2,44^{\mathrm{bc}}$ & $2,83^{\mathrm{de}}$ & $3,01^{\mathrm{c}}$ \\
\hline Faz. Rios dos Bois & $2,28^{\mathrm{cd}}$ & $1,52^{\mathrm{d}}$ & $1,85^{\mathrm{f}}$ & $1,61^{\mathrm{e}}$ \\
\hline Faz. Alcantilhado & $3,49^{\mathrm{a}}$ & $3,57^{\mathrm{a}}$ & $3,58^{\mathrm{abc}}$ & $2,55^{\mathrm{d}}$ \\
\hline Média (Mean) & 2,60 & 2,71 & 2,99 & 3,30 \\
\hline $\mathrm{CV}(\%)$ & 8,71 & 6,73 & 3,58 & 5,50 \\
\hline
\end{tabular}

Médias seguidas por letras iguais, na mesma coluna, não diferem entre si pelo teste Duncan $(P>0,05)$; $C V=$ coeficiente de variação. Means indicated by the same letters, in the same column, do not differ by Duncan range test ( $P>.05) ; C V=$ coefficient of variation.

Tabela 7 - Composição da carcaça de Podocnemis expansa com idade entre 23 e 29 meses, provenientes de criadouros comerciais $(n=5)$

Table 7 - Carcass composition of Podocnemis expansa from 23 to 29 months of age, from commercial flocks $(n=5)$

\begin{tabular}{|c|c|c|c|c|c|c|}
\hline \multirow[t]{3}{*}{$\begin{array}{l}\text { Criadouros } \\
\text { Commercial flocks }\end{array}$} & \multicolumn{6}{|c|}{$\begin{array}{c}\text { Composição porcentual da carcaça }(\%) \\
\text { Carcass percent composition }(\%)\end{array}$} \\
\hline & \multirow[t]{2}{*}{$\begin{array}{c}\text { MS } \\
\text { Dry mater }\end{array}$} & \multicolumn{2}{|c|}{$\begin{array}{c}\text { Proteína bruta } \\
\text { Crude protein }\end{array}$} & \multicolumn{2}{|c|}{$\begin{array}{l}\text { Extrato etéreo } \\
\text { Ether extract }\end{array}$} & \multirow[t]{2}{*}{$\mathrm{PB} / \mathrm{EE}$} \\
\hline & & $\begin{array}{l}\text { MU } \\
W M\end{array}$ & $\begin{array}{l}\text { MS } \\
D M\end{array}$ & $\begin{array}{l}\text { MU } \\
W M\end{array}$ & $\begin{array}{l}\text { MS } \\
D M\end{array}$ & \\
\hline Faz. Vale da Serra & $24,56^{\mathrm{a}}$ & $19,26^{\mathrm{a}}$ & $78,58^{\mathrm{a}}$ & $1,46^{\mathrm{b}}$ & $5,85^{\mathrm{b}}$ & $13,19^{\text {de }}$ \\
\hline Pró-Fauna & $22,69^{\mathrm{c}}$ & $18,15^{\mathrm{ab}}$ & $80,43^{\mathrm{a}}$ & $1,55^{\mathrm{ab}}$ & $6,68^{\mathrm{ab}}$ & $13,00^{\text {de }}$ \\
\hline Agrotec & $24,87^{\mathrm{a}}$ & $19,56^{\mathrm{a}}$ & $78,57^{\mathrm{a}}$ & $1,95^{\mathrm{a}}$ & $7,92^{\mathrm{a}}$ & $10,16^{\mathrm{e}}$ \\
\hline Faz. São Romão & $23,75^{\mathrm{ab}}$ & $18,29^{\mathrm{ab}}$ & $77,10^{\mathrm{a}}$ & $1,10^{\text {bcd }}$ & $4,62^{\mathrm{bc}}$ & $17,03^{\mathrm{de}}$ \\
\hline Faz. C. Redondo & $23,26^{\mathrm{ab}}$ & $18,37^{\mathrm{ab}}$ & $78,89^{\mathrm{a}}$ & $0,33^{\mathrm{e}}$ & $1,43^{\mathrm{e}}$ & $57,88^{a}$ \\
\hline Faz. Lambari & $21,49^{\mathrm{bc}}$ & $16,37^{\mathrm{bc}}$ & $76,73^{\mathrm{a}}$ & $0,49^{\mathrm{de}}$ & $2,29^{\mathrm{de}}$ & $37,38^{b}$ \\
\hline Faz. R. dos Bois & $20,10^{\mathrm{c}}$ & $15,62^{\mathrm{c}}$ & $77,88^{\mathrm{a}}$ & $0,74^{\text {cde }}$ & $3,88^{\mathrm{d}}$ & $21,18^{\mathrm{cd}}$ \\
\hline Faz. Alcantilhado & $17,68^{\mathrm{d}}$ & $13,42^{\mathrm{d}}$ & $75,64^{\mathrm{a}}$ & $0,87^{\mathrm{cd}}$ & $5,05^{\mathrm{bc}}$ & $15,88^{\text {de }}$ \\
\hline Média (Mean) & 22,30 & 17,38 & 77,98 & 1,09 & 4,79 & 22,48 \\
\hline $\mathrm{CV}(\%)$ & 7,62 & 9,09 & 6,44 & 25,86 & 26,02 & 29,41 \\
\hline
\end{tabular}

Médias seguidas por letras iguais, na mesma coluna, não diferem entre si pelo teste Duncan $(P>0,05)$; $C V=$ coeficiente de variação. Means indicated by the same letters, in the same column, do not differ by Duncan range test $(P>.05) ; C V=$ coefficient of variation.

$\mathrm{MU}=$ matéria úmida; $\mathrm{MS}=$ matéria seca .

$W M=$ wet matter; $D M=$ dry matter 
Tabela 8 - Coeficientes de correlação $(r)$ entre o peso corporal, o rendimento de carcaça e dados morfométricos do trato digestivo de $P$. expansa entre 23 e 29 meses $(n=160)$

Table 8 - Correlation coefficient $(r)$ among body weight (BW), carcass output and morphometrical data of the digestive tract of P. expansa from 23 to 29 months of age $(n=160)$

\begin{tabular}{lcccccc}
\hline & PC & CAR+VISC & CAR & CAR+CA & VISC & GORD \\
& BW & CAR+VISC & CAR & CAR + CA & VISC & $F A T$ \\
\hline CAR+VISC $($ CAR + VISC $)$ & 0,97 & & & & & \\
CAR $($ CAR & 0,97 & 0,97 & & & & \\
CAR+CA $($ CAR $+C A)$ & 0,97 & 0,96 & 0,97 & & & \\
VISC $($ VISC) & 0,86 & 0,91 & 0,81 & 0,81 & & \\
GORD $(F A T)$ & 0,81 & 0,77 & 0,79 & 0,79 & 0,63 & \\
\hline
\end{tabular}

$\mathrm{PC}=$ peso corporal; $\mathrm{CAR}+\mathrm{VISC}=$ carcaça com vísceras; $\mathrm{CAR}=$ carcaça sem vísceras; $\mathrm{CAR}+\mathrm{CA}=$ carcaça com carapaça; $\mathrm{VISC}=$ vísceras; GOR = gordura.

$P C=$ body weight CAR + VISC = carcass plus viscera; $C A R=$ carcass without viscera; $C A R+C A=$ carcass + carapace $;$ VISC = viscera; FAT = total fat.

\section{Conclusões}

Ainda que os animais apresentem peso médio inferior ao permitido para o abate, o rendimento de carcaça na ordem de $30 \%$ responde à necessidade do mercado, pois o peso vivo de $1,50 \mathrm{~kg}$ confere aproximadamente $450 \mathrm{~g}$ de carne com ossos.

A composição média do teor protéico e o baixo valor de extrato etéreo indicam bom valor nutricional da carne de tartaruga-da-amazônia.

\section{Literatura Citada}

ALHO, C.J.R.; CARVALHO, A.G.; PÁDUA, L.F.M. Ecologia da tartaruga-da-amazônia e avaliação de seu manejo na Reserva Biológica do Trombetas. Brasil Florestal, v.38, p.29-47, 1979.

ASHLEY, L.M. Laboratory anatomy of the turtle. Gainesville: WCB Brown Company Publishers, 1969. p. 18-23.

BRASIL. Portaria ${ }^{\circ} 142$ de 30 de dezembro de 1992. Normatiza a criação em cativeiro da tartaruga-da-amazônia, Podocnemis expansa e do tracajá Podocnemis unifilis com finalidade comercial, partindo de filhotes, nas áreas de distribuição geográfica. Diário Oficial [da] República Federativa do Brasil. Brasília, DF, 21 jan. 1993. p 922-923.

BRASIL. Portaria ${ }^{\circ} 70$ de 23 de agosto de 1996. Normatiza a comercialização de produtos das espécies de quelônios, Podocnemis expansa, tartaruga-da-amazônia, e Podocnemis unifilis, tracajá, provenientes de criadouros comerciais regulamentados pelo Ibama. Diário Oficial [da] União da República Federativa do Brasil. Brasília, DF, 26 ago., 1996. Seção I, p.16.390-16.391.

CANTARELLI, V.H. Manejo da fauna silvestre nas reservas de fauna da Amazônia: informe Brasil. Goiânia: [s.n.], 1999. 99p. Relatório.

CENAQUA. Conservação e criação comercial de quelônios. Goiânia: Centro Nacional dos Quelônios da Amazônia-Ibama, 1999. 34p. Mimeografado.

DUARTE, F.S. Diagnóstico da criação de quelônios e incubação artificial de ovos de tartaruga Podocnemis expansa no Amazonas. Manaus: Fundação Universidade do Amazonas, 1998. 76p. Monografia (Graduação em Engenharia Agronômica) - Fundação Universidade do Amazonas, 1998.
GASPAR, A.; RANGEL FILHO, F.B. Utilização de carnes de Tartarugas-da-amazônia, Podocnemis expansa, criadas em cativeiros, para consumo humano. In: CONGRESSO BRASILEIRO DE CIÊNCIA E TECNOLOGIA DE ALIMENTOS, 18., 2000, Fortaleza. Resumos... Fortaleza:SBCTA, 2000. resumo n.3.31. [s.p.].

LIMA, M.G.H.S. A importância das proteínas de origem animal e vegetal no primeiro ano de vida da tartarugada-amazônia - Podocnemis expansa (Schweigger, 1812). Manaus: Universidade do Amazonas e Instituto de Pesquisa da Amazônia, 1998. 93p. Dissertação (Mestrado em Ciência de Alimentos) - Universidade do Amazonas e Instituto de Pesquisa da Amazônia, 1998.

PÁDUA, L.F.M.; ALHO, C.J.R.; CARVALHO, A.G. Conservação e manejo da tartaruga-da-amazônia, Podocnemis expansa, na Reserva Biológica do Rio Trombetas (Testudines, Pelomedusidae). Brasil Florestal, v.54, p.43-53, 1983.

REIS, A.P.; DE MARCO Jr., P. Análise morfométrica de filhotes de tartaruga-da-amazônia, Podocnemis expansa (Schweigger, 1812) em criatórios comerciais. In: CONGRESSO BRASILEIRO DE ZOOLOGIA, 23., 2000, Cuiabá. Resumos... Cuiabá: Sociedade Brasileira de Zoologia/Universidade Federal de Mato Grosso, 2000. p.523.

ROZE, J.A. Piligrin of the river. Natural History, v.73, p.34-41, 1964.

SAMPAIO, I.B.M. Estatística aplicada à experimentação animal. Belo Horizonte: Fundação de Ensino e Pesquisa em Medicina Veterinária e Zootecnia, Universidade Federal de Minas Gerais, 1998. 221p.

SILVA, D.J. Análise de alimentos (métodos químicos e biológicos), 2.ed. Viçosa, MG: Universidade Federal de Viçosa, 1990. 165 p.

SILVA, C.S.; MELO, D.S.; RODRIGUES, E.C.P.G. et al. Consumo de produtos da fauna silvestre na cidade de Manaus. 1997. 24p. Trabalho apresentado à disciplina Conservação e Manejo de Fauna Silvestre. Faculdade de Ciências Agrárias, Universidade do Amazonas, Manaus, 1997.

SILVA NETO, P.B. Abate de tartarugas-da-amazônia. São Paulo: Pró-Fauna Assessoria e Comércio Ltda., Convênio Empresa Pro-Fauna/Cenaqua-Ibama, 1998. 48p. Relatório.

STAT SOFT, I. Statistica for windows. Tulsa, USA, 1996. Computer program manual.

R. Bras. Zootec., v.32, n.1, p.1-9, 2003

Recebido em: 29/06/01 Aceito em: 16/04/02 